\title{
Laparoscopic Herniotomy - A Single Centre Study of 150 Cases
}

\author{
Deepak Verma*, Deva Ram, Mukteshwar Gupta, Nemi Chand \\ Department of Surgery, Dr. Sampurnanand Medical College, Jodhpur, India \\ Email address: \\ drdeepakv@ymail.com (D. Verma) \\ ${ }^{*}$ Corresponding author \\ To cite this article: \\ Deepak Verma, Deva Ram, Mukteshwar Gupta, Nemi Chand. Laparoscopic Herniotomy - A Single Centre Study of 150 Cases. American \\ Journal of Clinical and Experimental Medicine. Vol. 5, No. 5, 2017, pp. 181-185. doi: 10.11648/j.ajcem.20170505.15
}

Received: August 18, 2017; Accepted: September 19, 2017; Published: September 20, 2017

\begin{abstract}
Pediatric patients presenting as inguinal hernia or congenital hydrocele is common ailment encountered in surgical practice and herniotomy is a very common surgical procedure performed. Open procedure is gradually being replaced by laparoscopic approach because of the distinct advantages of early recovery, short stay and better cosmetic results. 150 pediatric patients of inguinal hernia or congenital hydrocele were subject of this study. These patients were subjected to laparoscopic herniotomy performed at the neck of the sac and proximal part of peritoneum was closed with non-absorbable polypropyelene suture with aspiration of scrotal sac, if required. Average age of patients was 6.5 year with $93.35 \%$ male. $70.6 \%$ had inguinal hernia and $29.4 \%$ had congenital hydrocele). $68 \%$ patients had right sided and $10.6 \%$ clinically bilateral lesion. Operating time was 25 minutes in unilateral and 34.8 minutes in bilateral procedure. Postoperative stay was 1.06 days. No intraoperative complication was noted. Recurrence rate was $1.33 \%$ and conversion rate was $0.66 \%$. Laparoscopic herniotomy is safe, well tolerated and effective procedure with early recovery, short operating time, less postoperative pain, free of complication, shorter post-operative hospital stay and very low recurrence. It can detect contralateral patent processus vaginalis and bilateral closure of it can be done through same approach.
\end{abstract}

Keywords: Congenital Hydrocele, Processus Vaginalis, Contralateral Patent Processus Vaginalis, Herniotomy

\section{Introduction}

Inguinal hernia or hydrocele is one of the common ailment encountered in paediatric patients by surgeons and the incidence is higher in neonates and infants. However, the incidence decreases after first year of life. Premature infants have an even higher risk of developing inguinal hernia. Patent processus vaginalis [1] results in either congenital hydrocele or inguinal hernia depending on the size of the opening at internal inguinal ring in pediatric patients $[2,3,4]$. Since pathogenesis is related to patent processus vaginalis and descent of testis, incidence is more common in boys and on right side [3] due to late closure of internal ring as compared to left side. Clinical presentation is usually as painless inguinal or scrotal swelling which increases after cough, cry or long term play. Presence of pain indicates complications. Patient presenting as unilateral disease may have occult contralateral patent processus vaginalis.
Hence, inguinal hernia repair is one of the most commonly performed operations in the pediatric population [5]. Exposure, dissection, high ligation and removal of sac was first proposed treatment of inguinal hernia / hydrocele [6] and have been in use for many years as gold standard treatment of this ailment sans excision of sac. Traditionally, it is operated upon by open inguinal incision. However, with the introduction of laparoscopic repair, opinion of scientific community is divided concerning the best method of pediatric herniotomy [7]. Relatively small number prefer a laparoscopic repair over traditional open repair [5]. Smaller surface area for access, compliant abdominal wall, presence of liver below costal margin, intra-abdominal urinary bladder, smaller size abdominal cavity and viscera close to abdominal wall were various reasons of apprehension in using therapeutic laparoscopy in pediatric patients.

However, with changes in instrumentation for laparoscopy and increasing experience in adult laparoscopy, therapeutic laparoscopic procedures are increasing performed in pediatric 
patients. But relatively small number prefer a laparoscopic repair over the open repair for inguinal hernia repair. Laparoscopic repair presents a viable alternative to open repair and offers a number of benefits over traditional approach including superior visualization of the relevant anatomy, ability to assess and repair a contralateral hernia, lower rates of metachronous hernia, shorter operative time in bilateral hernia and improved cosmesis [5].

This study was, therefore, conducted on 150 paediatric patients between 1-14 years of age presenting either as inguinal hernia or hydrocele to assess feasibility and advantages of laparoscopic herniotomy.

\section{Material and Methods}

150 patients between 1-14 years of age presenting and clinically diagnosed as case of either inguinal hernia or congenital hydrocele were subjects of this study. Relevant routine investigations were performed and pre-anesthetic assessment was done by anesthetist for their fitness for general anesthesia. All these patients were planned for laparoscopic herniotomy i.e. division of hernia sac at neck followed by closure of the proximal part of divided sac by purse string suture using 2'0 non-absorbable polypropyelene suture material.

$6 \mathrm{~mm}$ sub umbilical camera port and two $6 \mathrm{~mm}$ midclavicular line working ports at umbilical level were created after pneumoperitoneum with $8 \mathrm{~mm}$ of $\mathrm{mg}$ intraabdominal pressure. Peritoneum at internal ring was divided with sharp dissection and 2'0 polypropyelene suture was used for applying purse string closure of proximal part of the peritoneum. Pneumoperitoneum was released and ports were closed. Hydrocele fluid was aspirated from scrotal sac by passing aspiration needle through scrotal skin. As a standard practice in paediatric herniotomy, distal sac was left intact with open end. Duration of surgery, post-operative pain and analgesic requirement, intra-operative or post-operative complications, post-operative hospital stay were recorded and compared with other laparoscopic and open herniotomy studies from literature.

\section{Results}

$48 \%$ patients were between 5 to 8 years of age and $14.6 \%$ were between 9 to 10 years of age. No patients below one year was operated in this study. $26.6 \%$ patients were between 1 to 3 years of age. Mean age of patients was $6.5+/-3.1$ years of age (confidence interval $6.5+/-0.495$ ). 93.3\% patients were male and the ratio of male: female was $14: 1$. $70.6 \%$ were diagnosed as inguinal hernia and $29.4 \%$ as congenital hydrocele.

$67.9 \%$ patients with inguinal hernia had lesion on right side and 9.3\% had bilateral lesion. In hydrocele group, $68.1 \%$ had right sided and $13.6 \%$ had bilateral lesion. Overall $68 \%$ had right side lesion and $10.6 \%$ were bilateral lesion following clinical examination.

During laparoscopic procedure, $13.43 \%$ patients, clinically diagnosed as unilateral lesion had small contralateral patent processes vaginalis and therefore, total patients having bilateral lesion increased from $10.6 \%$ to $22.6 \%$ after procedure.

In unilateral cases, operating time was 21 to 30 minutes in $52 \%$ patients and it was 11 to 20 minutes in $32 \%$ patients. In $14.6 \%$ patients, operating time was between 31 to 40 minutes. The time exceeded 40 minutes in one patients who was converted from laparoscopic to open herniotomy. In all bilateral herniotomies, time taken was between 31 to 40 minutes. Mean operating time was $25+/-6.3$ minutes (confidence interval $-25+/-1.007$ ) in unilateral cases and it was 34.8+/-5.6 minutes (confidence interval $34.8+/-0.895$ ) in bilateral cases.

According to the numerical pain scale, $87.7 \%$ patients had mild pain and $11.6 \%$ had moderate pain and.66\% had severe pain (converted to open) following recovery from anesthesia. Tramadol was used as analgesics in postoperative period. $34.6 \%$ required $50 \mathrm{mg}$ or less of tramadol, $44 \%$ required 76 to $100 \mathrm{mg}$ and $4 \%$ required more than $100 \mathrm{mg}$ of total tramadol. Mean requirement was $81.3+/-7 \mathrm{mg}$ (confidence interval $81.3+/-1.119$ ) of tramadol.

No intra-operative complication was reported and postoperatively $4 \%$ patients had surgical emphysema in early post-operative period. Patients were followed for 24 months and $1.33 \%$ had recurrence of disease. Re-laparoscopy was done in these patients and could be treated by laparoscopic re suturing sac. In $0.66 \%$ patients procedure was converted to open surgery because of adherent omentum to the sac

93.3\% patients had post-operative stay of 1 day and rest were discharged between 1-2 days. Average stay was 1.06+0.25 days (confidence interval $1.06+/-0.039$ ).

Degree of freedom was 149 and confidence interval was calculated at confidence level of $95 \%$.

\section{Discussion}

Galen in $176 \mathrm{AD}$ described processus vaginalis as a duct descending to testes as a small offshoot of the great peritoneal sac [1]. Shortly after the descent of testes, in first few months of life, most of processus vaginalis obliterates except the terminal portion around testes which persists as tunica vaginalis. According to variable data, in $40 \%$ of the infants, processus vaginalis closes during first few months of life and in another $20 \%$ by 2 years of age $[2,3]$. Failure of obliteration of processus vaginalis is responsible for pathogenesis of indirect inguinal hernia / hydrocele [1, 4]. Overall incidence of patent processus vaginalis is $12-14 \%$ whereas that of indirect inguinal hernia / hydrocele is $1-2 \%$, which indicates that all patent processus vaginalis do not manifest clinically. As the left testis descends before right, the right processus vaginalis closes later explaining the higher incidence of hernia and congenital hydrocele on right side in pediatric patients [3]. In present study also, $67.9 \%$ of patients with inguinal hernia and $68.1 \%$ of hydrocele patients had right side involved. 


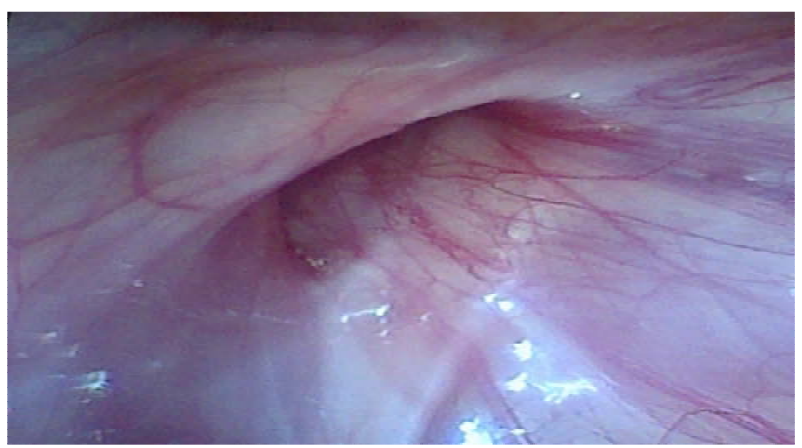

Figure 1. Defect Present in Internal Inguinal Ring.

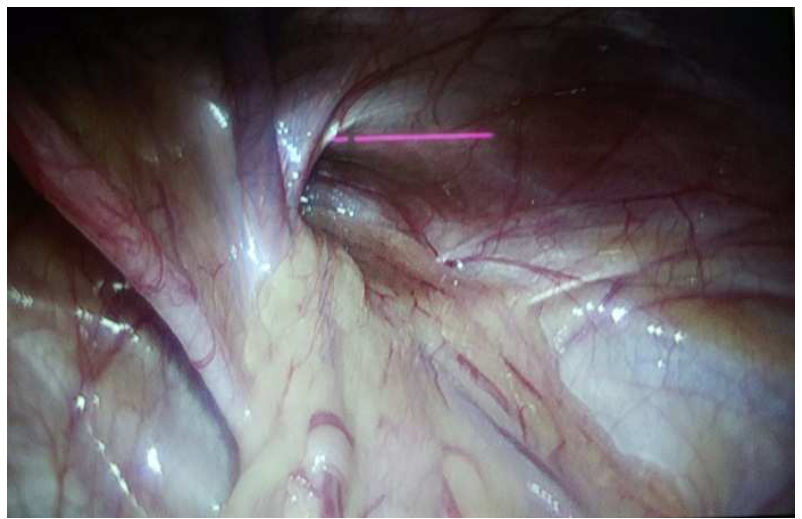

Figure 2. Hernial Sac Containing of Omentum.

Caliber of processus vaginalis at internal inguinal ring will determine whether patient will develop hernia or hydrocele. Small caliber channel will allow only peritoneal fluid to seep through leading to hydrocele and larger defect will allow intra-peritoneal viscera to migrate and manifest is inguinal hernia. $70.6 \%$ patients had inguinal hernia and $23.4 \%$ had hydrocele in this series.

Ferguson proposed closure of patent processus vaginalis by exposure, dissection, high ligation and removal of sac [6]. and this was successfully applied in pediatric patients for many years [8]. The Ferguson's principal sans excision of hernial sac is still the basis of all pediatric hernia repair even today. Various factors like smaller surface area and compliant abdominal wall, smaller size of abdominal cavity, location of viscera closes to abdominal wall, well developed structures like obliterated umbilical vein, artery and urachus were responsible for slow growth of therapeutic laparoscopy in pediatric patients. Introduction of sophisticated insufflator and monitoring equipment, availability of thin $(3 \mathrm{~mm})$ short instruments and increasing experience of laparoscopy in adult patients led to increasing use of therapeutic laparoscopy in pediatric patients.

Stephen Gans was first to perform laparoscopy in a hernia patient by introducing laparoscope through open hernial sac for verification of patent processus vaginalis on opposite side. Various techniques have been used for laparoscopic closure of patent processus vaginalis but faithful reproduction of the inguinal approach was developed lately which involves dissection and transection of the neck of the sac at internal inguinal ring followed by suture closure of proximal end [9]. Same technique was used in the present study. Since recurrence rate is significantly lower in repairs pertormed with non-absorbable suture [10] polypropyelene was used in this study

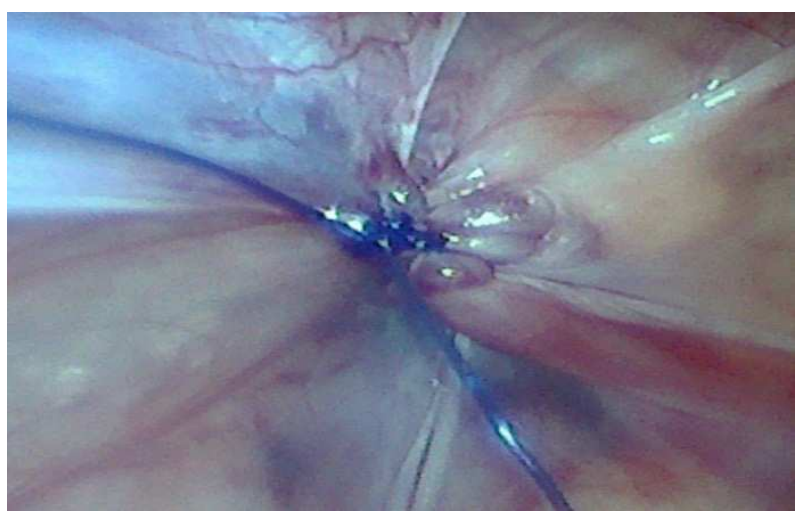

Figure 3. Purse-String Suturing of Hernial Sac.

Average age of patients in this study was $6.5+/-3.15$ years which is higher as compared to other studies [11, 12]. probably because majority of patients were from rural area with lack of health awareness. No patient below one year was operated in this study and in patients between 1-2 years $(13.3 \%)$ either the large size of hernia / hydrocele or history of at least one attack of obstruction was present. 93.3\% patients were male (14:1). Other authors have also reported high incidence of male patients [11]. 9.43\% of hernia and $13.6 \%$ of hydrocele patients (overall $10.6 \%$ ) had clinically detectable bilateral lesion. After the procedure, total of $22.6 \%$ had bilateral lesion suggesting contralateral patent processus vaginalis in additional $12 \%$ patients. This is the distinct advantage of laparoscopic herniotomy which detects contralateral clinically undetected patent processus vaginalis. All these bilateral cases could be treated through same ports providing better cosmetic results. Open surgical procedure would have necessitated another scar in opposite inguinal region. Similar observations were made by other authors also $[11,13,14,15]$. Chances of having contralateral patent processus vaginalis is high in patients below 2 years of age [15].

Average operating time in unilateral cases was $25+/-6.3$ minutes whereas in bilateral cases it was $34.8+/-5.6$ minutes. Many studies by other authors have compared the operating time of laparoscopic procedure with open procedure and reported shorter time with laparoscopy specially in bilateral cases $[11,13]$. However, time taken will depend on many factors including experience of surgeon and few authors have reported longer time with laparoscopy [16, 17]. Since assessment of postoperative pain is difficult in patients below 2 years of age, only patients above 2 years were evaluated in this study. $87.7 \%$ had mild and $11.6 \%$ had moderate pain. On numerical pain scale, average score was $1.88+/-1.07$. All patients were started oral fluids after 8 hours postoperatively, combination of Ibuprofen $(10-15 \mathrm{mg} / \mathrm{kg})$ and Paracetamol $(10-20 \mathrm{mg} / \mathrm{kg})$ was given after 8 hours, From 0 to 8 hours postoperatively, tramadol (1-2 $\mathrm{mg} / \mathrm{kg})$ was given parenterally. 
$78.6 \%$ patients required less than $100 \mathrm{mg}$ of tramadol in postoperative period. One patient converted to open had severe pain and required more than $100 \mathrm{mg}$ of total tramadol for adequate pain control.

No intraoperative complication was reported in this study, $4 \%$ patients had minor surgical emphysema subcutaneously which subsided within 24 hours. Patients were followed up for 24 months and $1.33 \%$ had recurrence during this period. Re-laparoscopy was done and it was observed that in both cases part of sac over gonadal vessels was missed during suturing. Both patients were treated laparoscopically. Avoiding the peritoneum over vas deferens and gonadal vessels during laparoscopic ligation of sac may leave a small gap at internal inguinal ring which has potential to contribute in recurrence in male patients $[9,11,18]$. Recurrence rate in laparoscopy varies from $0.88 \%$ to $3.1 \%[13,19]$ which is similar to open procedure. Few authors have reported higher rate of recurrence in laparoscopic herniotomy [20]. It was very low $(1.33 \%)$ in present study.

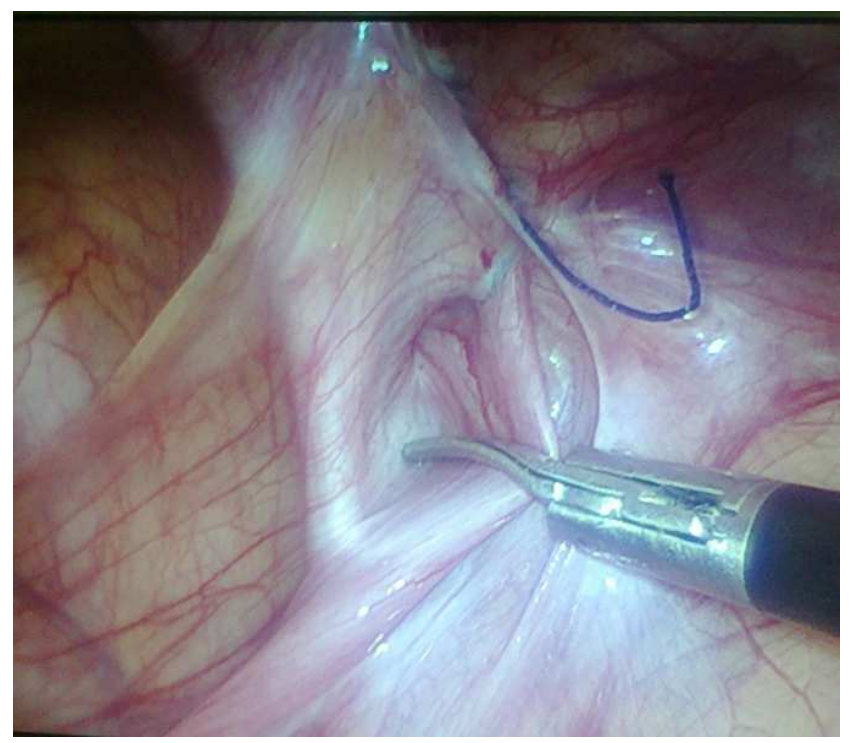

Figure 4. Small Sac in Case of Recurrence after Laparoscopic Herniotomy.

Postoperative stay in $93.3 \%$ was 1 day with an average of $1.06+-0.25$ days. And conversion rate was $0.66 \%$. Conversion to open in single patient was required due to adherent omentum which could not be reduced laparoscopically and operating time was also more than 40 minutes in this patient only. Various authors have reported different conversion rates and it varies from 0 to $10 \%[21$, 22]. Laparoscopic repair in recurrent childhood inguinal hernia cases, developed after open repair, avoids entering a fibrotic inguinal canal, making the procedure easier and shorter and hence laparoscopic hernia repair is a good alternative options in recurrent childhood hernia [23].

Laparoscopic pediatric hernia repairs is beneficial in bilateral hernia of girls, giant hernia, recurrent following failed repair and in hernia associated with undescended testis or ambiguous genitalia [7]. Safety and efficacy of laparoscopic hernia repair especially in female patients and in patients with initial left sided hernia [24]. In comparison with open herniotomy, shorter operative time for unilateral as well as bilateral hernias, less post-operative complications was also observed without an difference in recurrence rate $[25,26,27]$.

\section{Conclusion}

Present study, therefore, indicates that laparoscopic herniotomy for pediatric patients is safe, effective, takes less operating time and have very few complications including recurrence. Postoperative pain, analgesic requirement and hospital stay is also less. It had an added advantage of detecting contralateral patent processus vaginalis with ability to treat bilateral cases with best cosmetic result. Laparoscopic hernioraphy is good option for recurrent childhood hernia developed after open repair. However, recurrence rate is same as open procedure as observed in this study. Similar observations were made by many authors regarding laparoscopic herniotomy.

\section{References}

[1] Singer C. Galen on Anatomical procedures. London 1956, Oxford University Press - Nyhus HM, Harkin HN. Hernia, Philadelphia, 1964. JB Lippincott.

[2] Miltenburg DM, Nuchtern JG, Jaksic T, Kozinetiz C, Brandt ML. Laparoscopic evaluation of the pediatric hernia; a metaanalysis. J Pediatr Surg 1998; 33 (6): 874-9.

[3] Van Wessem KJ, Simons MP, Plaisier PW, Lange JF. The ethiology of indirect inguinal hernias: congenital and/or acquired? Hernia 2003; 7 (2): 76-9.

[4] Rowe MI, Copelsom LW, Clatworthy HW. The patent processus vaginalis and inguinal hernia. J Pediatr Surg 1969; 4: 102-7.

[5] Feehan BP, Fromm DS, Laparoscopic Pediatric Inguinal Hernia Repair: Overview of "True Herniotomy" Technique and Review of Current Evidence. S. D. Med, 2017: 70 (5): 217-223.

[6] Ferguson AH, Oblique inguinal hernia: a typical operation for its radical cure. JAMA 1899; 33: 6 .

[7] Potts WJ, Riker WL, Lewis JE. The treatment of inguinal hernia in infants and children. Ann Surg 1950; 132: 566.

[8] Raveenthiran V, Agarwal P. Choice of Repairing Inguinal Hernia in Children: Open versus Laparoscopy. Indian J Pediatr, 2017; 84 (7): 555-563.

[9] Tsai YC, Wu CC, Yang SSD. Open versus minilaparoscopic herniorraphy for children: a prospective comparative trial with midterm follow-up evaluation. Surg Endosc. 2010; 24 (1): 21-4.

[10] Grimsby GM, Keays MA, Villanuava C, Bush NC, Shodgrass WT, Gargolid PC et al. Non-absorbable sutures are associated with lower recurrence rates in laparoscopic percutaneous inguinal hernia ligation. J Paediatr Urol, 2015; 11 (5) 275 e 1-4.

[11] Saranga Bharathi, Arora M, Baskaran V. Pediatric inguinal hernia: laparoscopic versus open surgery. JSLS 2008; 12: 27781 . 
[12] Hassan ME, Mustafawi AR. Laparoscopic flip-flap technique versus conventional inguinal hernia repair in children. JSLS 2007; 11: 90-3.

[13] Chinnaswamy P, Malladi V, Jani KV, Parthasarthi R, Shetty RA, Kovalakat AJ et al. Laparoscopic hernia repair in children. JSLS 2005; 9 (4): 393-8.

[14] Abdul Rahman A. Laparoscopic versus open inguinal herniotomy in infants and children: a meta-analysis. Pediatr Surg Int 2011; 27 (6): 605-12.

[15] Liu C, Chin T, Jas SE, Wei C. Intraoperative laparoscopic diagnosis of contralateral patent processus vaginalis in children with unilateral inguinal hernia. Br J Surg 1995; 82: 106-8.

[16] Koivusalo AI, Korpela R, Wirtavouri K, Piiparinen S, Rintala RJ, Pakarinen MP. A single-blinded randomized comparison of laparoscopic versus open hernia repair in children. Pediatrics 2009; 123: 332-7.

[17] Chan KL, Hui WC, Tam PK. Prospective randomized singlecenter, single-blinded comparison of laparoscopic vs open repair of pediatric inguinal hernia. Surg Endosc 2005; 19: 927-32.

[18] Ozgediz D, Roayaie K, Lee H, Nohuhara KK, Farmer DL, Bratton B et al. Subcutaneous endoscopically assisted ligation (SEAL) of the internal ring for repair of inguinal hernias in children: report of a new technique and early results. Surg Endosc 2007; 21 (8): 1327-31.

[19] Endo M, Watanbe T, Nakano M, Yoshida F, Ukiyama E, Laparoscopic completely extraperitoneal repair of inguinal hernia in children: a single institute experience with 1,257 repairs compared with cut-down herniorraphy. Surg Endosc 2009; 23 (8): 1706-12.
[20] Yang C, Zhang H, Pu J, Mei H. Laparoscopic vs open herniorraphy in the management of pediatric inguinal hernia; a systemic review and meta-analysis. J Pediatr Surg 2011; 46 (9) $1824-34$.

[21] Chen MK, Schropp KP, Lobe TE. Complications of minimalaccess surgery in children. J Pediatr Surg 1996; 31: 1161-5.

[22] Ylidz A, Celebi S, Akin M, Karadag CA, Sever N., Erginel B et al. Laparoscopic hernioraphy: a better approach for recurrent hernia in boys. Paediatr Surg Int, 2012: 28 (5): 44953.

[23] Nah SA, Giacomelo L, Eaton S, De Coppi P, Curry JI, Drake DP et al. Surgical repair of incarcerated inguinal hernia in children: laparoscopic or open. Eur J Pediatr Surg: 2011; 21 (5): 8-11.

[24] Zhu LL, Yu WJ, Liu JB, Huang X, Lv ZB. Comparison of laparoscopic hernia repair and open herniotomy in children: a retrospective cohort study. Hernia, 2017; 221 (3): 417-423.

[25] Feng S, Zhao L, Liao Z, Chen X. Open versus laparoscopic inguinal herniotomy in children: A systematic review and meta-analysis focusing on post-operative complications. Surg Laparosc Endosc Percutan Tech. 2015; 625 (4): 275-80.

[26] Shalaby R, Ibrahem R, Shahin M, Yehya A, Razek MA, Alsayaad A et al. Laparoscopic hernia repair versus open herniotomy in children: a controlled randomized study. Minim Invasive Surg. 2012; 2012: 484135, doi: 10.1155/2012 /484135Epub 2012 Dec27.

[27] Glaskee S, Glass M, Tapador P, Matthussens L, Phillipe P. A true laparoscopy herniotomy in children: evaluation of long term result. J Laparoendos Adv Surg Tech A. 2010; 20 (2): 191-4 doi: 10,1089/Lap.2009.0069. 